\title{
Cytochrome Oxidase Analyses of Bacillus Strains: Existence of Oxidase-Positive Species
}

\author{
PETER JURTSHUK, JR., * AND JONG-KANG LIU \\ Department of Biology, University of Houston, Houston, Texas 77004
}

\begin{abstract}
Analyses of 173 Bacillus strains (representing 30 species) with a newly developed quantitative colorimetric $N, N, N^{\prime}, N^{\prime}$-tetramethyl-p-phenylenediamine oxidase assay revealed the presence of many oxidase-positive species. Of 144 mesophilic strains analyzed, the following were oxidase positive: 16 of 16 Bacillus alvei strains, 7 of 9 Bacillus laterosporus strains, 5 of 10 Bacillus circulans strains, 4 of 5 Bacillus macerans strains, 2 of 5 Bacillus firmus strains, 1 strain of Bacillus sphaericus, and 1 strain of Bacillus brevis. The thermophilic organisms Bacillus stearothermophilus T-10 and ATCC 8005, "Bacillus caldotenax" (one strain), and "Bacillus thermodenitrificans" DSM 465 were also oxidase positive. In fact, when the oxidase-positive thermophilic strains were grown at $65^{\circ} \mathrm{C}$, they exhibited very high oxidation rates; most of these rates were equivalent to the high rates of reaction recorded for strains of Pseudomonas aeruginosa and Neisseria spp. Most mesophilic Bacillus strains and all of the psychrophiles examined were oxidase negative or oxidase indeterminate (the latter had oxidase rates equilavent to the rates in the $N, N, N^{\prime}, N^{\prime}$-tetramethyl-p-phenylenediamine autooxidation reaction). Spectral absorbance analyses on membranes of oxidase-positive $B$. alvei strain 385 revealed the presence of a type $c$ cytochrome with cytochrome oxidases $o$ and $a+a_{3}$; Bacillus pumilus strains which could not oxidize $N, N, N^{\prime}, N^{\prime}$-tetramethyl-p-phenylenediamine lacked type $c$ cytochromes but possessed these two oxidases. The paper strip Kovacs oxidase test with Marion reagent could be routinely used for detecting oxidase-positive Bacillus strains. A distinct class of oxidase-positive strains should be identified, which might eventually be useful for identification studies.
\end{abstract}

The oxidase test has been used extensively in studies on gram-negative bacteria since it was introduced in 1928 by Gordon and McCleod (5). The use of the oxidase test for gram-positive organisms has been somewhat limited $(8-10$, 15 ), but it has been used to examine differences between the staphylococci and micrococci $(1,3$, 16). Quantitative $N, N, N^{\prime}, N^{\prime}$-tetramethyl-pphenylenediamine (TMPD) oxidase studies have shown that "Sarcina flava," "Sarcina luteus," and Sporosarcina urea strains are quite active, the latter sporeformer being usually active $(8,9$, 11). Previous reports have stated that Bacillus strains can give "equivocal" oxidase reactions (15), and one report specifically stated that an unexpectedly large number of soil sporeforming isolates were oxidase positive (4). The results of other, more recent studies suggest that TMPD (a redox dye), which is commonly used as the oxidase reagent, may be impermeable in grampositive microrganisms $(3,6,8,9)$. Thus, the relevance of the oxidase reaction in gram-positive cells has been questioned.

In this report we describe a distinct class of oxidase-positive Bacillus spp. which can be detected experimentally. The quantitative capabili- ty of some of these Bacillus strains to oxidize reduced TMPD to Wurster blue (9) approaches the high rates previously reported for Azotobacter vinelandii, Pseudomonas aeruginosa, and Neisseria spp. (8-11). Such oxidase-positive $B a$ cillus cultures are readily detected by the qualitative Kovacs paper strip test (13). In our recent studies we found oxidase-positive strains among mesophilic Bacillus alvei, Bacillus circulans, Bacillus firmus, Bacillus laterosporus, Bacillus macerans, Bacillus sphaericus, and Bacillus brevis. Of 24 thermophilic strains examined, 18 were found to be highly oxidase positive; among these were Bacillus stearothermophilus strains T-10 and ATCC 8005, "Bacillus thermodenitrificans" strain DSM 465 and one "B. caldotenax" strain.

(Preliminary reports of the results have been presented elsewhere [Jurtshuk and Liu, Abstr. XIII Int. Congr. Microbiol., Boston, Mass., p. 62, 1982; Liu and Jurtshuk, Abstr. Annu. Meet. Am. Soc. Microbiol. 1983, K122, p. 197].)

For the standard colorimetric oxidase assay, bacteria were grown for $20 \mathrm{~h}$ on tryptic soy agar (Difco Laboratories, Detroit, Mich.) at the appropriate temperature. Colonies were directly 
washed off petri plates with the aid of sterile glass rods, and whole cells were harvested by centrifugation at $6,000 \mathrm{rpm}(4,340 \times \mathrm{g})$ and $25^{\circ} \mathrm{C}$. The pellets were washed three times in $0.02 \mathrm{M}$ $\mathrm{KH}_{2} \mathrm{PO}_{4}$ buffer ( $\mathrm{pH} 6.0$ ), and a $3.0-\mathrm{ml}$ bacterial suspension (in $0.02 \mathrm{M} \mathrm{KH}_{2} \mathrm{PO}_{4}$ buffer, $\mathrm{pH} 6.0$ ) was prepared and turbidimetrically standardized to $0.20 \pm 0.02$ optical density unit at $610 \mathrm{~nm}$ with a Bausch \& Lomb Spectronic 20 colorimeter. TMPD oxidation was initiated by adding $20 \mu \mathrm{l}$ of a $1.2 \%(\mathrm{wt} / \mathrm{vol})$ TMPD-hydrochloride solution. Wurster blue formation $(\Sigma \mathrm{mM}=12.0)$ was monitored at $610 \mathrm{~nm}$ at 5 -min intervals for 15 min; specific activities were calculated by using the initial 5-min reaction rate and are reported on the basis of cellular dry weight. Analysis of 107 bacterial cultures having the standard turbidity given above revealed a dry weight mean \pm standard error of $0.194 \pm 0.007 \mathrm{mg} / \mathrm{ml}$ (standard deviation, $0.0729 \mathrm{mg} / \mathrm{ml}$ ). The type of spectrophotometric TMPD oxidase assay described above was first described by Lieberman and Lanyi in 1971 for use in studies on bacterial electron transport systems (14). The use of this assay with bacterial whole cells has been documented previously by Jurtshuk et al. (Abstr. Annu. Meet. Am. Soc. Microbiol. 1980, C191, p. 306), who described the parameters and precautions necessary for rapidly quantifying bacterial TMPD oxidase reactions.

Figure 1 shows the TMPD oxidation rate patterns for three representative Bacillus strains, B. alvei strain 385 , Bacillus megaterium strain $\mathrm{UH}$, and Bacillus pumilus strain $\mathrm{UH}$. Similarly, standardized suspensions of a laboratory strain of $P$. aeruginosa and Escherichia coli strain B (Fig. 1, dashed lines) served as the oxidase-positive and -negative controls, respectively. TMPD oxidation in the absence of bacterial cells (autooxidation control) is also plotted in Fig. 1 (dotted line); this reaction started at "true" zero. For all specific activity calculations (Table 1) the TMPD autooxidation control rate was corrected for by subtraction.

As shown in Fig. 1, the rate of TMPD oxidation by $B$. alvei strain 385 cells approached the high rate observed for the oxidase-positive $P$. aeruginosa strain. In fact, analyses of 15 other $B$ alvei strains showed that strain 385 cells gave the lowest specific activity (Table 1 ) of all the $B$. alvei strains examined. $B$. megaterium strain UH had a TMPD oxidation rate that approached the rate of the autooxidation control; this reaction rate was typical of organisms having oxidase-indeterminate reactions. TMPD oxidation by cells by $B$. pumilus strain UH was essentially negative, much like the oxidation observed for $E$. coli strain B. The negative base-line reaction observed with cells of $E$. coli (and somewhat with cells of $B$. pumilus) suggests that such

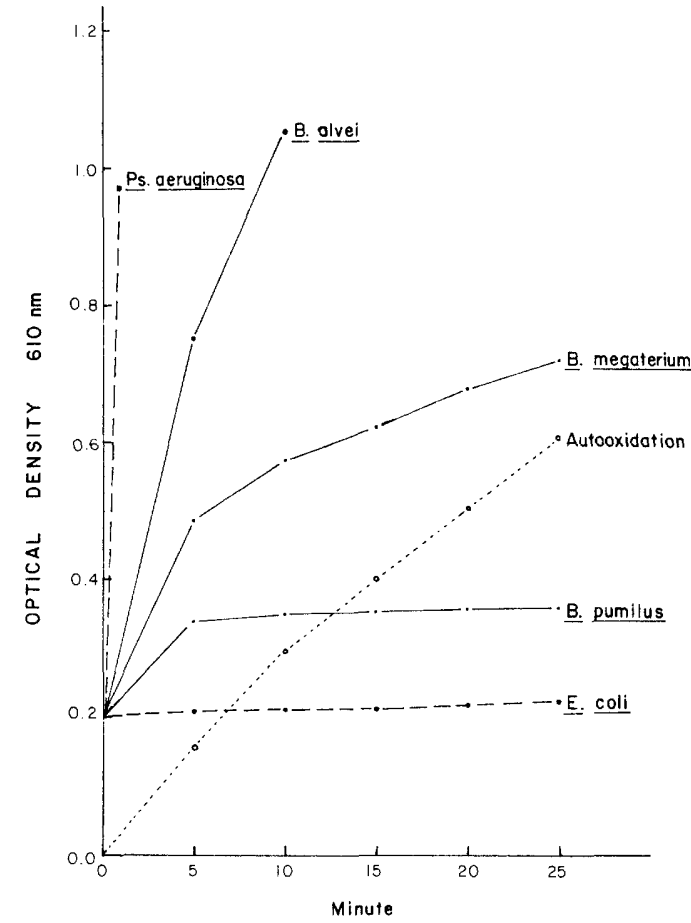

FIG. 1. Oxidation of TMPD by standardized resting cell suspensions of $P$. aeruginosa strain $\mathrm{UH}, B$ alvei strain $385, B$. megaterium strain UH, $B$. pumilus strain $\mathrm{UH}$, and $E$. coli strain $\mathrm{B}$. The oxidation rates for $P$. aeruginos $a$ and $B$. alve $i$ cells are characteristic of oxidase-positive strains. The rate shown for $B$. megaterium cells is oxidase indeterminate; the overall TMPD oxidation rate is equivalent to the rate of the autooxidation control (dotted line). Cells of $B$. pumilus and $E$. coli are the least active, and the reaction patterns shown for these two organisms are characteristic of oxidase-negative strains. For the colorimetric TMPD oxidase assay, the bacterial cells were turbidimetrically standardized at $610 \mathrm{~nm}$ to $0.20 \pm 0.02$ optical density unit in $3.0 \mathrm{ml}$ of $0.02 \mathrm{M} \mathrm{KH}_{2} \mathrm{PO}_{4}$ buffer (pH 6.0). The TMPD oxidation reaction was then initiated by adding $1.0 \mu \mathrm{mol}$ of reduced TMPD (final concentration, $3.3 \times 10^{-4} \mathrm{M}$ ). Wurster blue formation was monitored at $610 \mathrm{~nm}$ and was plotted as a function of time. For this study, a prolonged 25 -min reaction interval was used to observe particularly the reaction patterns for the oxidase-indeterminate $(B$. megater $u m$ ) and oxidase-negative (B. pumilus and $E$. coli) strains. The autooxidation control (dotted line), which starts at true zero, optically represents the rate of TMPD oxidation that occurred in the absence of bacterial cells.

oxidase-negative organisms have functional oxidases with high affinities for binding molecular $\mathrm{O}_{2}$ yet are not TMPD dependent. Such cytochrome oxidases would remove oxygen from solution (via normal respiration) so that $\mathrm{O}_{2}$ would no longer be available for autooxidation of TMPD. Quantitative TMPD oxidase analyses 
TABLE 1. Oxidase-positive Bacillus strains exhibiting high TMPD oxidase activities

\begin{tabular}{|c|c|c|c|c|c|c|c|}
\hline Organism & Source $^{a}$ & $\begin{array}{l}\text { Growth } \\
\text { temp } \\
\left({ }^{\circ} \mathrm{C}\right)\end{array}$ & $\mathrm{Sp} \mathrm{act}{ }^{b}$ & Organism & Source $^{a}$ & $\begin{array}{l}\text { Growth } \\
\text { temp } \\
\left({ }^{\circ} \mathrm{C}\right)\end{array}$ & Sp act ${ }^{b}$ \\
\hline B. stearothermophilus & P. Saunders & 55 & 2.636 & B. alvei White colony & $\mathrm{UH}$ & 32 & 1.062 \\
\hline $\mathrm{T}-10$ & & & & B. circulans No. 4 & Pasteur & 32 & 1.044 \\
\hline "B. thermodenitrifi- & F. Pinchoty & 55 & 2.443 & & Institute & & \\
\hline $\begin{array}{c}\text { cans'” DSM } 465 \\
\text { Bacillus } \text { sp. strain }\end{array}$ & SHSU & 55 & 1.856 & $\begin{array}{l}\text { B. macerans NCTC } \\
6355\end{array}$ & L. Seldin & 32 & 1.043 \\
\hline NGB 101 & & & & Bacillus sp. strain RS & R. Sharp & 55 & 1.025 \\
\hline B. alvei $\mathrm{B}-4300$ & NRRL & 32 & 1.672 & 173 & & & \\
\hline B. alvei B-387 & NRRL & 32 & 1.562 & B. alvei B-386 & NRRL & 32 & 1.014 \\
\hline $\begin{array}{l}\text { Bacillus sp. strain RS } \\
20\end{array}$ & R. Sharp & 55 & 1.501 & B. macerans No. 2 & $\begin{array}{l}\text { Pasteur } \\
\text { Institute }\end{array}$ & 32 & 1.004 \\
\hline B. alvei $\mathrm{B}-397$ & NRRL & 32 & 1.483 & "B. caldotenax" & R. Sharp & 55 & 0.962 \\
\hline B. alvei 29 & DSM & 32 & 1.453 & B. circulans No. 3 & Pasteur & 32 & 0.960 \\
\hline Bacillus sp. strain & SHSU & 55 & 1.442 & & Institute & & \\
\hline NGB 301 & & & & B. alvei B-384 & NRRL & 32 & 0.946 \\
\hline B. brevis B-335 & NRRL & 32 & 1.402 & B. alvei 385 & $\mathrm{UH}$ & 32 & 0.937 \\
\hline B. macerans No. 3 & $\begin{array}{l}\text { Pasteur } \\
\text { Institute }\end{array}$ & 32 & 1.401 & B. firmus No. 1 & $\begin{array}{l}\text { Pasteur } \\
\text { Institute }\end{array}$ & 32 & 0.922 \\
\hline B. alvei $\mathrm{B}-383$ & NRRL & 32 & 1.362 & B. laterosporus SHSU & SHSU & 32 & 0.916 \\
\hline B. alvei $\mathrm{B}-4010$ & NRRL & 32 & 1.356 & B. sphaericus No. 2 & Pasteur & 32 & 0.885 \\
\hline B. alvei $\mathrm{F}$ & G. S. Byng & 32 & 1.340 & & Institute & & \\
\hline B. circulans No. 7 & $\begin{array}{l}\text { Pasteur } \\
\text { Institute }\end{array}$ & 32 & 1.290 & $\underset{43}{\text { Bacillus } \text { sp. strain RS }}$ & R. Sharp & 55 & 0.862 \\
\hline B. alvei B-385 & NRRL & 32 & 1.242 & B. laterosporus NRS & R. Gordon & 32 & 0.839 \\
\hline Bacillus sp. strain NC & SHSU & 55 & 1.242 & 590 & & & \\
\hline 1101 & & & & B. stearothermophilus & R. Sharp & 55 & 0.664 \\
\hline B. alvei $\mathrm{B}-4186$ & NRRL & 32 & 1.231 & ATCC 8005 & & & \\
\hline $\begin{array}{l}\text { Bacillus sp. strain NC } \\
\quad 902\end{array}$ & SHSU & 55 & 1.222 & B. firmus No. 2 & $\begin{array}{l}\text { Pasteur } \\
\text { Institute }\end{array}$ & 32 & 0.648 \\
\hline $\begin{array}{l}\text { Bacillus sp. strain } \\
\text { MHS } 1601\end{array}$ & SHSU & 55 & 1.220 & $\begin{array}{l}\text { B. laterosporus NCTC } \\
6357\end{array}$ & L. Seldin & 32 & 0.615 \\
\hline B. circulans No. 5 & $\begin{array}{l}\text { Pasteur } \\
\text { Institute }\end{array}$ & 32 & 1.176 & $\begin{array}{l}\text { Bacillus } \text { sp. strain EP } \\
\quad 136\end{array}$ & R. Sharp & 55 & 0.558 \\
\hline B. alvei $\mathrm{B}-4185$ & NRRL & 32 & 1.166 & B. laterosporus No. 2 & Pasteur & 32 & 0.515 \\
\hline B. alvei $\mathrm{B}-382$ & NRRL & 32 & 1.151 & & Institute & & \\
\hline $\begin{array}{l}\text { Bacillus sp. strain FH } \\
2301\end{array}$ & SHSU & 55 & 1.139 & $\begin{array}{l}\text { B. laterosporus NRS } \\
1647\end{array}$ & R. Gordon & 32 & 0.465 \\
\hline B. circulans No. 2 & $\begin{array}{l}\text { Pasteur } \\
\text { Institute }\end{array}$ & 32 & 1.137 & $\begin{array}{l}\text { Bacillus sp. strain RS } \\
\quad 241\end{array}$ & R. Sharp & 55 & 0.465 \\
\hline $\begin{array}{l}\text { Bacillus sp. strain FH } \\
2101\end{array}$ & SHSU & 55 & 1.130 & B. laterosporus No. 3 & $\begin{array}{l}\text { Pasteur } \\
\text { Institute }\end{array}$ & 32 & 0.464 \\
\hline B. macerans No. 1 & $\begin{array}{l}\text { Pasteur } \\
\text { Institute }\end{array}$ & 32 & 1.129 & B. laterosporus No. 1 & $\begin{array}{l}\text { Pasteur } \\
\text { Institute }\end{array}$ & 32 & 0.430 \\
\hline B. alvei B-4009 & NRRL & 32 & 1.121 & Bacillus sp. strain RS & R. Sharp & 55 & 0.428 \\
\hline $\begin{array}{l}\text { Bacillus sp. strain } \\
\text { MHS } 1701\end{array}$ & SHSU & 55 & 1.118 & 93 & & & \\
\hline
\end{tabular}

a SHSU, Sam Houston State University; NRRL, U.S. Department of Agriculture Northern Regional Research Center; DSM, Deutsche Sammlung von Microorganismen; UH, University of Houston.

${ }^{b}$ Micromoles of TMPD oxidized per hour per milligram (dry weight).

of 173 Bacillus strains, representing 30 species, showed this same degree of diversity. In this report we focus on (i) those Bacillus spp. which were highly oxidase positive (Table 1) and conversely (ii) those species which were distinctly oxidase negative and gave zero TMPD oxidation reaction rates, similar to the rate observed for $B$. pumilus or $E$. coli or both.

Table 1 lists representative Bacillus strains (and their sources) having high oxidase specific activities. Of the 144 mesophilic Bacillus strains tested, all 16 strains of $B$. alvei, as well as 7 of 9 strains of $B$. laterosporus, were found to be highly oxidase positive. Also highly active were 4 of $5 \mathrm{~B}$. macerans strains, 5 of $10 \mathrm{~B}$. circulans strains, 2 of $5 \mathrm{~B}$. firmus strains, 1 of $3 B$. sphaericus strains and one strain of $B$. brevis. Interestingly, two strains that were received originally as $B$. alvei cultures were consistently oxidase negative. These strains were subsequently found to be misidentified; one was a strain of Bacillus licheniformis, and the other 


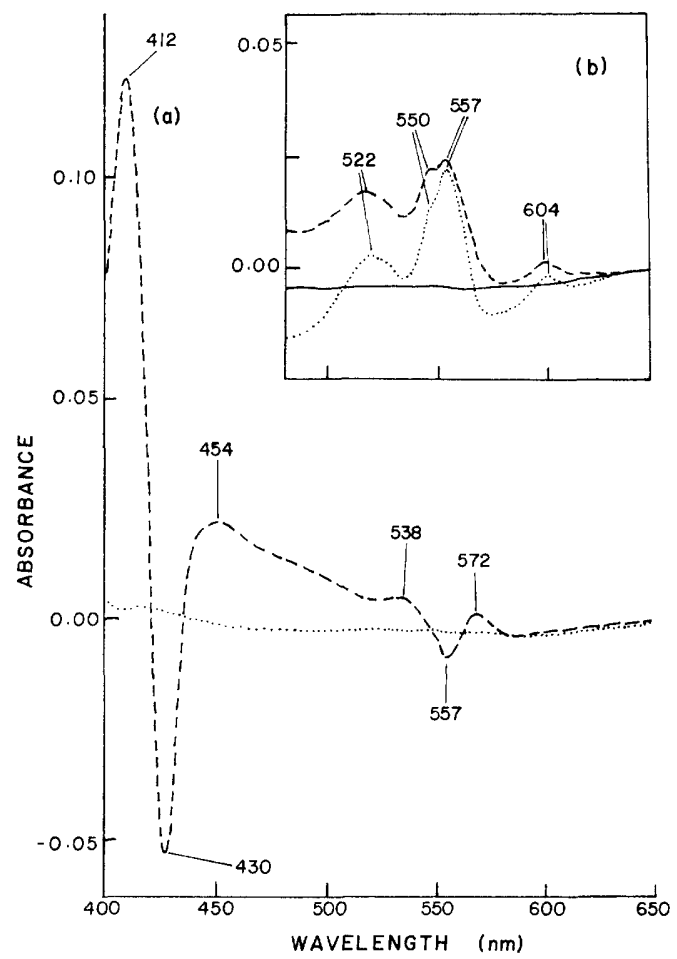

FIG. 2. Difference spectra of a partially purified TMPD-dependent cytochrome oxidase (protein concentration, $1.6 \mathrm{mg} / \mathrm{ml}$ ) isolated from respiratory membranes of $B$. alvei strain 385 . The carbon monoxidedithionite-reduced spectrum (a) shows large concentrations of cytochrome $o(0.65 \mathrm{nmol} / \mathrm{mg}$ of protein). (b) Dithionite-reduced minus oxidized spectrum, with alpha peaks of cytochromes $a, o$, and $c$ at 604,557 , and $550 \mathrm{~nm}$, respectively. The dotted line shows the absorbance changes after bubbling $\mathrm{CO}$. For further details see reference 12 .

was a strain of B. megaterium (Ruth E. Gordon, personal communication). Without exception, all $16 \mathrm{~B}$. alvei strains which we tested were oxidase positive. Conversely, only 2 of 32 cultures originally received as Bacillus polymyxa were highly oxidase positive. These two $B$. polymyxa strains were examined by R. E. Gordon; one was found to be a strain of $B$. laterosporus, and the other was most probably a $B$. brevis strain. In one respect, the heterogeneity and diversity of TMPD oxidation by Bacillus strains are quite surprising. Most gram-positive heterotrophs exhibit a "homogenous" cytochrome pattern (namely, cytochromes $b, c$, $a+a_{3}$, and $o$ ); thus, in theory, the TMPD oxidase reactions of Bacillus spp. should depend on whether type $c$ cytochrome is present and functionally integrated with type $o$ and $a$ cytochrome oxidases $(7,11)$. Since most Bacillus species analyzed were oxidase negative, if any of these organisms contained both type $c$ and type $o$ cytochromes, this finding would suggest that there are cellular impermeability problems that would affect TMPD oxidation.

The following mesophilic Bacillus strains were oxidase negative, as determined by the quantitative colorimetric oxidase test: 4 of $8 \mathrm{~B}$. circulans strains, including strain ATCC 9500; $B$. licheniformis strain SHSU; five B. megaterium strains, including strain Starka $899 ; 30$ of 30 $B$. polymyxa strains; $B$. pumilus strains LMD 68.28, F.8, F.10, 48.24, and UH; and "Bacillus thuringiensis subsp. pakistani' strain HD-395.

Most of the thermophilic sporeforming strains tested were unidentified hot spring isolates. In our survey, the highest rate of TMPD oxidase activity was observed in $B$. stearothermophilus T-10 cells grown at $65^{\circ} \mathrm{C}$; specific activities of more than 5.0 were obtained, whereas specific activities of $2.636 \mu \mathrm{mol} / \mathrm{h}$ per $\mathrm{mg}$ (dry weight) were found for cells grown at $55^{\circ} \mathrm{C}$ (Table 1). All sporeforming thermophiles showed this same activity pattern; substantially higher TMPD oxidase rates were found in cells grown at $65^{\circ} \mathrm{C}$ than in cells grown at $55^{\circ} \mathrm{C}$. All thermophilic strains grew poorly at $43^{\circ} \mathrm{C}$, and such cells had even lower specific activities (range, 1.4 to 1.9 ). In a study by Wolf and Sharp (17), 8 of 12 thermophilic Bacillus strains examined for oxidase activity were found to be oxidase positive with a qualitative paper strip test.

All 11 psychrophilic Bacillus strains analyzed (at $23^{\circ} \mathrm{C}$ ) were either oxidase negative or oxidase indeterminate. The least active were "Bacillus psychrophilus" strains W5 and W10A and Bacillus globisporus subsp. globisporus strain T26A; the most active strain was " $B$. psychrophilus" strain W16A, whose specific activity was approximately 0.40 (oxidase indeterminate).

Analyses of 11 mesophilic $B$. megaterium strains also produced interesting results; 5 strains were oxidase negative. One $B$. megateri$u m$ strain exhibited an oxidase value of 0.260 , thus falling in the oxidase-indeterminate group. A similar observation was made previously by Downs and Jones (2), who noted that respiratory membranes isolated from $B$. megaterium strain $\mathbf{M}$ (which had type $c: o$ and $a$ cytochromes) had TMPD oxidation values that were 5 to 10 times greater than the values for comparable membranes isolated from $B$. megaterium strain D440 (which lacked type $c$ cytochrome). This finding could explain the metabolic diversity of oxidase activities observed for the $11 \mathrm{~B}$. megaterium strains which we tested. Similar observations were made for 24 strains of $B$. thuringiensis. TMPD oxidase activities ranged from $0 \mu \mathrm{mol}$ of TMPD/h per mg (dry weight) for " $B$. thuringiensis subsp. pakistani"' to $0.351 \mu \mathrm{mol}$ of TMPD/h per $\mathrm{mg}$ (dry weight) for " $B$. thuringiensis subsp. entomocidus." 
We attempted to identify the components responsible for TMPD oxidase activity in $B$. alvei strain 385 and $B$. laterosporus strain SHSU. Respiratory membranes were isolated from $B$. alvei strain 385 , and a partial purification of the TMPD oxidase enzyme complex was carried out by using the procedure developed for $A$. vinelandii (12). An active solubilized cytochrome oxidase complex was isolated, and this complex was similar to the one described previously for $A$. vinelandii. The $B$, alvei strain 385 oxidase consisted of a cytochrome $c: o$ complex containing a small concentration of cytochrome $a+a_{3}$; the absorption spectrum is shown in Fig. 2. The carbon monoxide-dithionite difference spectrum (Fig. 2a) shows the major CO-reacting component(s), and the presence of a large concentration of type $o$ cytochrome $(0.65 \mathrm{nmol} / \mathrm{mg}$ of protein) was observed, with major Soret peak at $412 \mathrm{~nm}$ and a prominent sharp trough at $430 \mathrm{~nm}$. Alpha and beta peaks reacting with $\mathrm{CO}$ were found at 572 and $583 \mathrm{~nm}$, respectively, and there was a minor but characteristic carbon monoxide-cytochrome $o$ trough at $557 \mathrm{~nm}$. The presence of the type $c$ cytochrome was marked by the peak at $550 \mathrm{~nm}$ (Fig. 2b). The dithionitereduced components of the oxidase (Fig. 2b, dashed line) revealed a type $a$ cytochrome at 604 $\mathrm{nm}$ and the alpha peak of cytochrome $o$ at 557 $\mathrm{nm}$. The dotted line in Fig. $2 \mathrm{~b}$ shows the extent of $\mathrm{CO}$ reactivity of the cytochrome components in this partially purified oxidase preparation. The results of spectral analyses of the cytochrome components in the respiratory membranes of $B$. alvei strain $\mathrm{UH}$ and $B$. laterosporus strain SHSU (Table 1) were similar to the results obtained with $B$. alvei strain 385 . However, cytochrome analyses of membranes isolated from $B$. pumilus strain $\mathrm{UH}$ revealed that type $c$ cytochrome was absent but both oxidases (cytochromes $o$ and $a+a_{3}$ ) were present. The results of our spectral studies on the cytochrome components of Bacillus strains are consistent with the observation that bacterial TMPD oxidations still require type $c$ cytochrome(s) integrated with a terminal oxidase of cytochrome $o$ or $a+a_{3}$ (812).

We are grateful to Ruth E. Gordon, American Type Culture Collection, Rockville, Md., who provided essential taxonomic information and helped by identifying strains received as misidentified species. We also thank the following investigators for providing many of the Bacillus strains used in this study: H. de Barjac, Pasteur Institute, Paris, France; Harold F. Foerster, Sam Houston State University, Huntsville, Tex.; Lucy Seldin, Institute of Microbiology, Federal University of Rio de Janeiro, Rio de Janeiro, Brazil; and H. T. Dulmage, Cotton Insects Research Unit, U.S. Department of Agriculture, Brownsville, Tex. "B. thermodenitrificans"' strain DSM 465 (from F. Pinchinoty) and B. stearothermophilus strain T10 (from Priscilla Saunders) were obtained courtesy of Manley
Mandel. All psychrophillic Bacillus strains were kindly provided by John Larkin, Department of Microbiology, Louisiana State University, Baton Rouge. We also thank the following individuals for providing numerous other Bacillus strains used in this study: Dieter Claus, Deutsche Sammlung von Microorganismen, Gottingen, Germany; Laurence K. Nakamura, U.S. Department of Agriculture Northern Regional Research Laboratory, Peoria, Ill.; Graham S. Byng and Roy A. Jensen, State University of New York at Binghamton, Binghamton and R. Sharp, PHLS Center for Applied Microbiology, Porton, Salisburg, United Kingdom.

\section{LITERATURE CITED}

1. Boswell, P. A., G. F. Batstone, and R. G. Mitchell. 1972 The oxidase reaction in the classification of the Micrococcaceae. J. Med. Microbiol. 5:267-269.

2. Downs, A. J., and C. W. Jones. 1975. Energy conservation in Bacillus megaterium. Arch. Microbiol. 105:159167.

3. Faller, A., and K. H. Schleifer. 1981. Modified oxidase and benzidine tests for separation of staphylococci from micrococci. J. Clin. Miocrobiol. 13:1031-1035.

4. Goodfellow, M. 1968. Properties and composition of the bacterial flora of a pine forest soil. J. Soil Sci. 19:154-167.

5. Gordon, J., and J. W. McLeod. 1928. The practical application of the direct oxidase reaction in bacteriology. $J$. Pathol. Bacteriol. 31:185-190.

6. Hollander, R. 1977. The influence of permeability of the cell membrane on TMPD oxidase activity. Zentralbl. Bakteriol. Parasitenkd. Infektionskr. Hyg. Abt. 1 Orig. Reihe A 237:351-357.

7. Jones, C. W. 1980 . Cytochrome patterns in classification and identification including their relevance to the oxidase test, p. 127-138. In M. Goodfellow and R. G. Board (ed.), Microbiological classification and identification. Academic Press Inc., New York.

8. Jurtshuk, P., Jr., and D. N. McQuitty. 1976. Survey of oxidase-positive and -negative bacteria using a quantitative Kovacs oxidase test. Int. J. Syst. Bacteriol. 26:127135.

9. Jurtshuk, P., Jr., and D. N. McQuitty. 1976. Use of a quantitative oxidase test for characterizing oxidative metabolism in bacteria. Appl. Environ. Microbiol. 31:668679.

10. Jurtshuk, P., Jr., T. J. Mueller, and W. C. Acord. 1975. Bacterial terminal oxidases. Crit. Rev. Microbiol. 3:399468.

11. Jurtshuk, P., Jr., T. J. Mueller, D. N. McQuitty, and W. H. Riley, 1978. The cytochrome oxidase reaction in Azotobacter vinelandii and other bacteria, p. 99-121. In H. Degn, D. Lloyd, and G. C. Hill (ed.), Functions of alternative terminal oxidase. Proceedings of the 11th FEBS Copenhagen Meeting. Pergamon Press, Oxford.

12. Jurtshuk, P., Jr., T. J. Mueller, and T. Y. Wong. 1981. Isolation and purification of the cytochrome oxidase of Azotobacter vinelandii. Biochim. Biophys. Acta 637:374382 .

13. Kovacs, N. 1956. Identification of Pseudomonas pyocyanea by the oxidase reaction. Nature (London) 178:703.

14. Lieberman, M. M., and J. K. Lanyi. 1971. Studies on the electron transport chain of extremely halophilic bacteria. Biochim. Biophys. Acta 245:21-33.

15. Steel, K. J. 1961. The oxidase reaction as a taxonomic tool. J. Gen. Microbiol. 25:297-306.

16. Steel, K. J. 1962. The oxidase activity of staphylococci. J. Appl. Microbiol. 25:445-447.

17. Wolf, J., and R. J. Sharp. 1981. Taxonomic and related aspects of thermophiles within the genus Bacillus, p. 251296. In R. C. W. Berkeley and M. Goodfellow (ed.), The aerobic endospore forming bacteria. Academic Press, Inc., London. 